\title{
The Effect of Surface Vibration on Spray Evaporative Cooling
}

\author{
A. Sarmadian ${ }^{1}$, J. F. Dunne ${ }^{1}$, C. A. Long ${ }^{1}$, J-P Pirault ${ }^{1}$, J. Thalackottore-Jose ${ }^{1}$, Cedric Rouaud ${ }^{2}$, \\ ${ }^{1}$ Department of Engineering and Design/University of Sussex \\ BN1 9QT, Brighton, UK \\ a.sarmadian@sussex.ac.uk \\ ${ }^{2}$ Ricardo plc \\ West Sussex BN43 5FG, Shoreham-by-Sea, UK
}

\begin{abstract}
An experimental investigation of the effect of surface vibration on spray evaporative cooling has been undertaken using a dynamic test rig. The horizontal circular test section involved a spray nozzle on top of a shaker being shaking at different frequencies and amplitudes to examine the effect of vibration on the nucleate boiling regime. The combination of the two-phase spray cooling and dynamic surface conditions has not previously been studied. The results clearly show that dynamic surface conditions influence nucleate boiling. In general, the evidence shows that vibration impedes heat transfer. The influence of amplitude and frequency are shown however not to have the same trend for all the excess temperatures. Depending on the mechanism, combinations of amplitude and frequency can either increase or decrease the heat transfer coefficient compared with the static cooling surface.
\end{abstract}

Keywords: Spray Cooling, Vibration, Frequency, Amplitude, Nucleate boiling, Heat transfer

\section{Introduction}

Spray cooling is fast becoming a promising method of cooling systems with high heat removal requirements such as electronic and electrical components. In recent years, there has been increasing interest in spray cooling mechanisms for different cooling purposes [1], including high-flux at low-temperature [2], and at high-temperature [3]. Spray evaporative cooling has several major advantages in comparison to the conventional forced-convection cooling. First, it benefits from higher heat transfer rates owing to the role of the latent heat transfer mechanism compared to the sensible heat transfer mechanism associated with conventional single-phase. Second, spray cooling requires much lower mass-flow rates. Therefore, spray evaporative cooling results in a substantial reduction in the required coolant mass, and additionally in a significant reduction in pumping power. Moreover, owing to the nature of two-phase flow, it provides a more uniform temperature across all cooling surfaces, therefore eliminating hot spots. This key aspect is vital in a number of cases including thermal management of electronic components and battery stacks in electric vehicles, where there is an essential requirement to protect against overheating and fires. Further possible applications can be found such as in cooling highly-boosted internal combustion engines in conventional vehicles (to improve the knock control), and for cooling range extender engines in hybrid electric vehicles, Jafari et al. [4].

A comprehensive understanding of the different flow regimes of spray cooling plays a vital role in thermal management for the design of future cooling systems. In general, the flow patterns associated with sprays impinging on a surface consists of a nucleate-boiling mode, a transition followed by critical heat flux (CHF), and a film-boiling regime [5]. Fig. 1 shows a typical flow pattern map using the coordinates of heat flux and superheat temperature (i.e. the difference between the sprayed surface temperature and the saturation temperature). In fact, much of the current literature on spray cooling pays particular attention to the models and correlations that can predict such heat transfer mechanisms, which are important for design. By contrast, vibration is considered to have an impact on the heat transfer [6]. A recent study by Sathyabhama et al. [7] investigated the pool-boiling. (There are no published experimental studies in the literature addressing spray cooling involving nucleate boiling). The results of the study [7] concluded that at low frequencies (10Hz) and amplitudes $(2.5 \mathrm{~mm}$ ) vibration has a positive influence on heat transfer coefficient (by 26\%) compared to when there is no vibration. At high frequencies and amplitudes, vibration however was shown to impede boiling. It would therefore be expected that there is an intermediate optimum value. For spray cooling in two-phase flow nucleate boiling, the only investigation in the presence of surface vibration can be found in [8], involving a numerical study of single and multiple 
droplet impact on the surface performed by the volume of fluid (VOF) method [8]. Such a preliminary study considering only a number of droplets, cannot be used in modelling, thermal management, or system design of spray cooling systems especially under dynamic conditions (e.g. automotive). Therefore, there is a significant gap for further investigation. The objectives of the current study is, for the first time, to investigate the effect of vibration on nucleate boiling for a full-cone spray impinging on a flat circular copper test piece driven by a shaker.

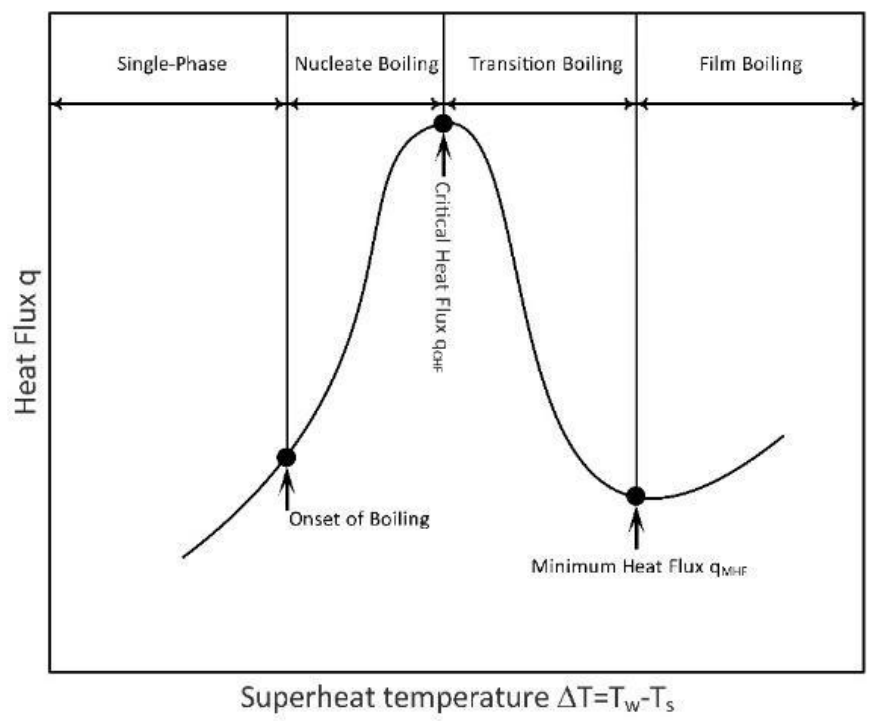

Fig. 1. Spray flow pattern map (boiling curve)

\section{Experimental Test Rig and Data Collection}

The test rig comprises the following components: a pump (Micropumps MGD100P) suppling de-ionised water to a fullcone UNIJET $^{\circledR}$ nozzle (TG tip Type, ranging from 0.16 litres/min at $1.5 \mathrm{bar}$, to 0.39 litres $/ \mathrm{min}$ at $10 \mathrm{bar}$ ) which is located on top of the test chamber. Second, a separation tank where vapour and liquid are separated and delivered to the condenser and condensate tank. Third, an air-cooled condenser (Denso RDP 583) where vapour from the test chamber is vented through a throttle valve; a miniature heat exchanger which is used to cool the condensate (at exit from the condenser) to below the maximum operating temperature of the pump $\left(100{ }^{\circ} \mathrm{C}\right)$. Two $345 \mathrm{~W}$ band-heaters (see the feed heater in Fig. 2) with a controllable 0 to $5 \mathrm{~V}$ power regulator (United Automation, EVR-25BF, AC Burst Fire Controller) used to heat the feed-water to the nozzle to obtain different degrees of sub-cooling (i.e. the difference between saturation and inlet temperatures) by a PID controller in CRIO-9035 National Instrument. Two digital pressure transducers (Omega PXM309) are linked to the data acquisition system to provide a constant record of the chamber pressure and the nozzle pressure difference. A low-flow turbine meter (Omega FLR1009ST-D) is installed just after the pump to measure the flow-rate, and is used as a state variable for the PID controller in FPGA CRIO-9035 to control the pumping voltage, in order to be able to have constant flow rates during experimentation. A header tank is also fitted at the highest point in the circuit to remove air and provide a positive feed. Fig. 2 demonstrates the overall schematic view of the test rig. 


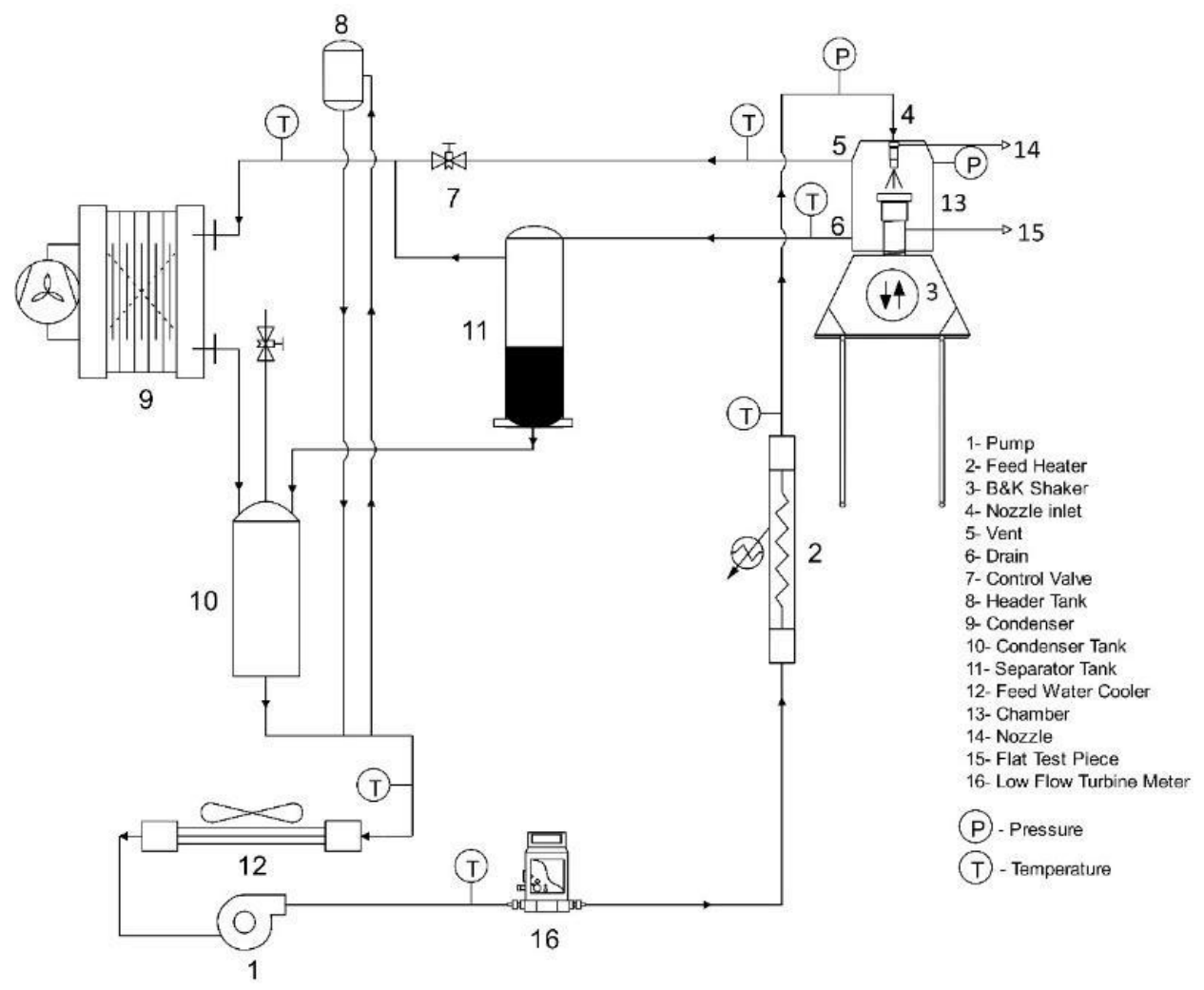

Fig. 2. Schematic view of the test setup

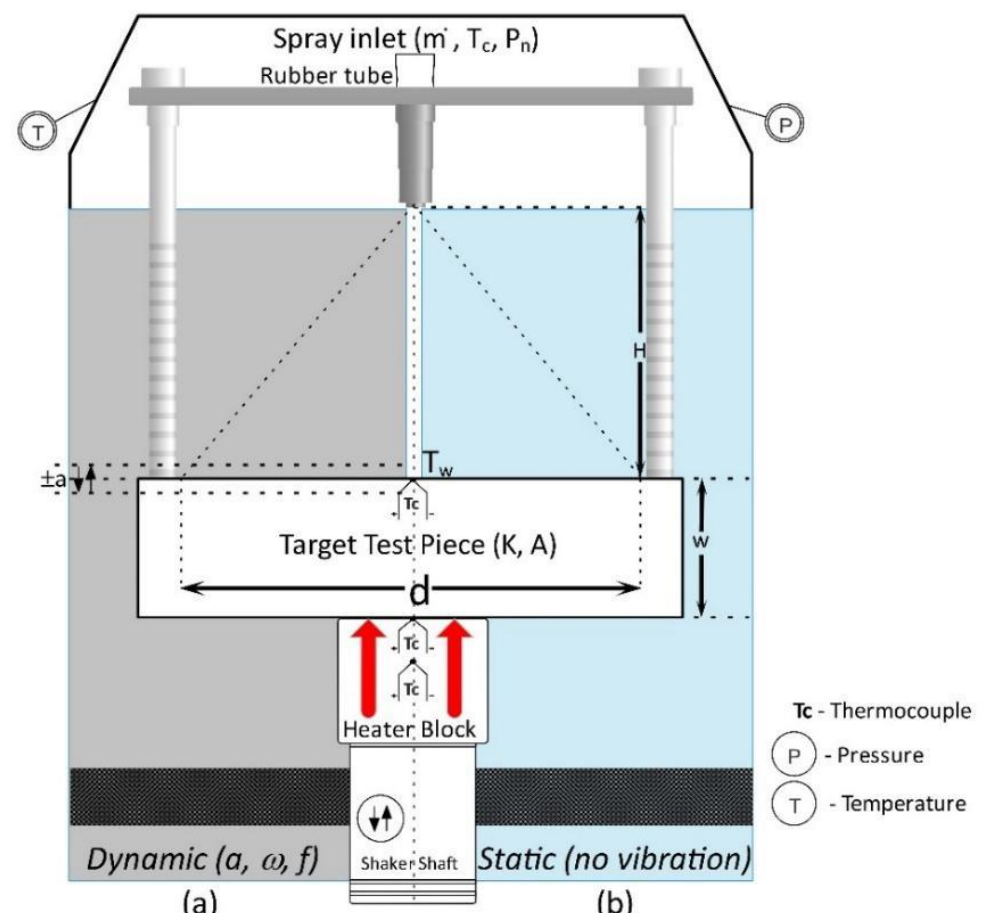

(a)

(b) 
Fig. 3. Spray system configuration inside the chamber under: (a) dynamic and (b) static conditions. (Not to scale.)

As shown in Fig. 3, the test piece is located in a chamber mounted on a Bruel \& Kjaer V555 mechanical shaker. Thus, the test piece and the nozzle inside the chamber can be simultaneously shaken at different frequencies $(f)$ and amplitudes (a). A Piezotronics PCB A 353B15 accelerometer $(10.27 \mathrm{mV} / \mathrm{g}, 1 \mathrm{~Hz}-10 \mathrm{kHz})$ is attached to the bottom of the drive shaft attached to the shaker head. Corresponding acceleration signals were measured by a National Instruments data acquisition system. The amplitude and frequency of the shaker was controlled using a Feedback Instruments FG600 signal generator with pure sine wave option. The test chamber is heated by six Watlow $250 \mathrm{~W}$ cartridge heaters controlled by 0 to $5 \mathrm{~V}$ signals from a NI9264 module and a power regulator (EVR-25BF). The test piece is a copper disc with a radius of $1 \mathrm{~cm}$. It has a smooth surface and a thermal conductivity of $385 \mathrm{Wm} / \mathrm{K}$. Three T Type thermocouples are used, the first of which is located 1 millimetre under the coolant surface of the test chamber followed by two more evenly located 5.5 millimetres underneath each other to facilitate the heat flux measurement capabilities.

\section{Data Reduction}

A test plan for this empirical study is supplied in Table 1. Overall, 18 test runs have been undertaken under static and dynamic conditions (respectively with and without vibration) at frequencies varying from $10 \mathrm{to} 400 \mathrm{~Hz}$, and with amplitude in the range from \pm 0.02 to $\pm 01 \mathrm{~mm}$.

Table 1: Test plan and operating parameters.

\begin{tabular}{|c|c|c|c|c|c|c|c|c|}
\hline $\begin{array}{c}P_{\text {chamber }} \\
\text { (bar) }\end{array}$ & $\begin{array}{c}v \\
(\mathrm{ml} / \mathrm{min} \\
)\end{array}$ & $\begin{array}{c}T_{\text {coolant }} \\
\text { (C) }\end{array}$ & Static & $\begin{array}{l}f(\mathrm{~Hz}) \\
a \\
(\mathrm{~mm})\end{array}$ & 10 & 100 & 200 & 400 \\
\hline \multirow{3}{*}{1} & \multirow{3}{*}{$\begin{array}{l}140, \\
160, \\
\text { and } \\
180\end{array}$} & \multirow{3}{*}{$\begin{array}{c}\text { Cons } \\
\text { tant } \\
\text { at } \\
80 \pm 1 \\
.5^{\circ} \mathrm{C}\end{array}$} & & 0.02 & - & & & \\
\hline & & & & 0.1 & & - & - & - \\
\hline & & & & 1 & & - & - & - \\
\hline
\end{tabular}

During each test-run the data for any new state was collected between 3 to 7 minutes (depending on the thermal inertia) after changing the cartridge heater loads to make sure that the system reached the steady state conditions. A test-run for the case study involving static cooling surfaces with a flow rate of $180 \mathrm{ml} / \mathrm{min}$ was conducted twice for the purposes of checking repeatability of the test facility. The heat flux was calculated using a solution for the one-dimensional conduction equation:

$$
q=-K \frac{d T}{d x}
$$

Using measurements taken from thermocouples embedded in the test piece, where $K, d T$ and $d x$ are the thermal conductivity, the temperature difference, and the distance between the top and the bottom thermocouples located in the test piece, respectively. The uncertainty analysis was done by using the method proposed by Moffat [9] according to:

$$
\delta R=\left[\sum_{i=1}^{n}\left(\frac{\partial R}{\partial X_{i}} \delta X_{i}\right)^{2}\right]^{\frac{1}{2}}
$$


Where $\delta R$ is the uncertainty of the dependent parameter, $\frac{\partial R}{\partial X_{i}}$ is sensitivity coefficient, and $\delta X_{i}$ is the error of the independent parameter in the measurement. The uncertainty in the determination of heat flux is within $3 \%$ for all the test runs.

\section{Results and Discussion}

In this section, the effect of volumetric flow rate on the heat flux, and the effect of frequency and amplitude of vibration will be separately investigated. Finally, the equivalent heat flux curves (with and without mechanically-induced vibration) will be compared to better understand the influence of vibration on the nucleate boiling regime.

\subsection{Static - Effect of Volumetric Flow Rate And Mass Flux}

Fig. 4 shows the results obtained for static test-runs representing the steady state data points of heat flux versus the excess temperature $\left(\Delta T_{\text {excess }}=T_{\text {surface }}-T_{\text {saturation }}\right)$ at three different flow rates of 140,160 , and $180 \mathrm{ml} / \mathrm{min}$. The highest and the lowest heat fluxes are $3072.5 \mathrm{~kW} / \mathrm{m}^{2}$ and $271.5 \mathrm{~kW} / \mathrm{m}^{2}$ at 160 and $180 \mathrm{ml} / \mathrm{min}$. As the trend shows, having higher flow-rate resulted in a higher heat-flux from 140 to $160 \mathrm{ml} / \mathrm{min}$. However, it has a reverse trend after a threshold at around $180 \mathrm{ml} / \mathrm{min}$ where the equivalent heat fluxes are less than those for $160 \mathrm{ml} / \mathrm{min}$. This effect is assumed to stem from the fact that after a higher mass-flow rate, and consequently a higher pressure difference around the nozzle (here from 1.6 to 2.3 bar), the angle of the spray cone increases. Increased spray cone-angle at $180 \mathrm{ml} / \mathrm{min}$ means lower mass-flux covering the test piece, and therefore it provides less heat-transfer compared to that for a lower volumetric flow rate of $160 \mathrm{ml} / \mathrm{min}$. However, as can be seen from Fig. 4 (b) (a zoomed-plot of Fig. 4) at the excess temperature of $4{ }^{\circ} \mathrm{C}$, there is a reverse in the trend where the heat-flux of higher volumetric flow rate is noticeably higher. The reason for this trend can again be due to the effect of increased cone-angle, which changes the direction of droplet impact onto the thin liquid film on top of the surface. Such an incident makes a lower penetration impact lead to the advent of nucleation owing to less suppression force in front of bubble departure from nucleation sites. Leading the advent of the nucleate boiling regime to a lower surface temperature, enhances the heat transfer coefficient at the same excess temperature.

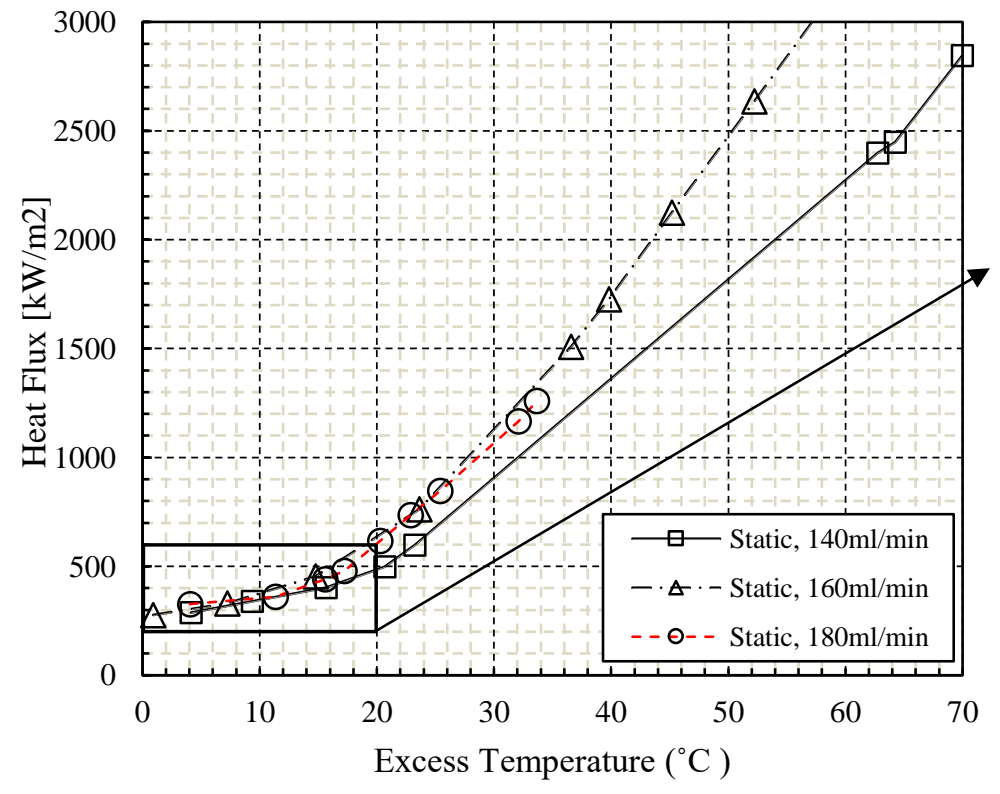

(a)

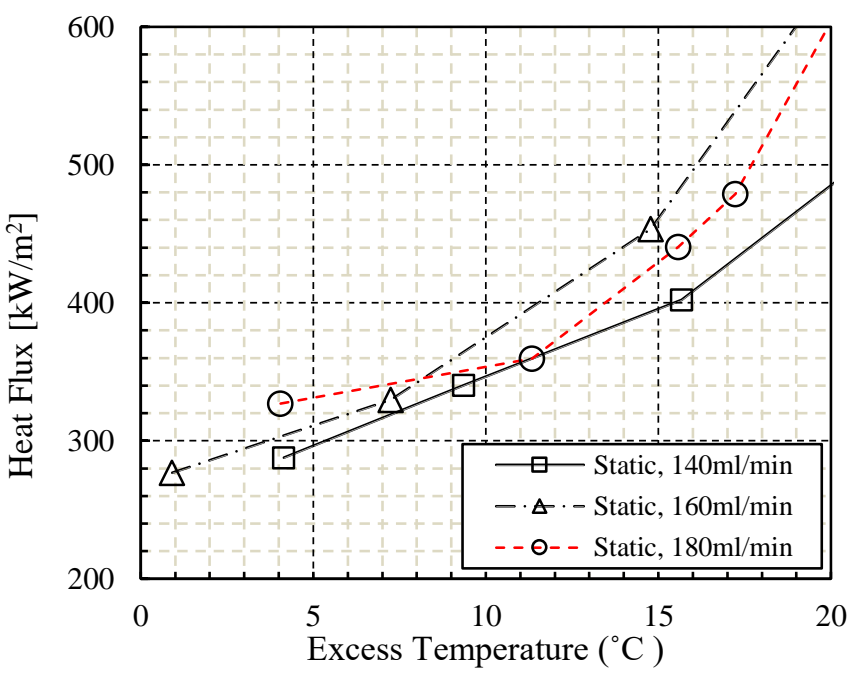

(b)

Fig. 4. The trend of heat flux changes with the change of excess temperature for static test runs. 


\subsection{Dynamics - The Effect of Frequency and Amplitude}

To understand how frequency can affect the trend of the nucleate boiling curve, results with quite a low amplitude of $0.02 \mathrm{~mm}$, and three high frequencies of 100, 200, and $400 \mathrm{~Hz}$, are shown in Fig. 5. Considering the lower excess temperature regions (i.e. from 0 to $30^{\circ} \mathrm{C}$ ) heat-flux does not follow the changes in frequency, although a small decrease in heat-flux from increasing frequency is evident in the results. On the other hand, for the excess temperature above $30{ }^{\circ} \mathrm{C}$, the gradient of the curves is identical to the heat transfer coefficient slopes at a higher angle by increasing frequency. This effect gets more intense with a higher flow-rate of $180 \mathrm{ml} / \mathrm{min}$ as the gaps between the curves gradually expand by any increment in frequency and excess temperature. This clearly indicates that there is a definite effect of frequency on the heat transfer either augmentation or deterioration depending on the mechanism of nucleation.
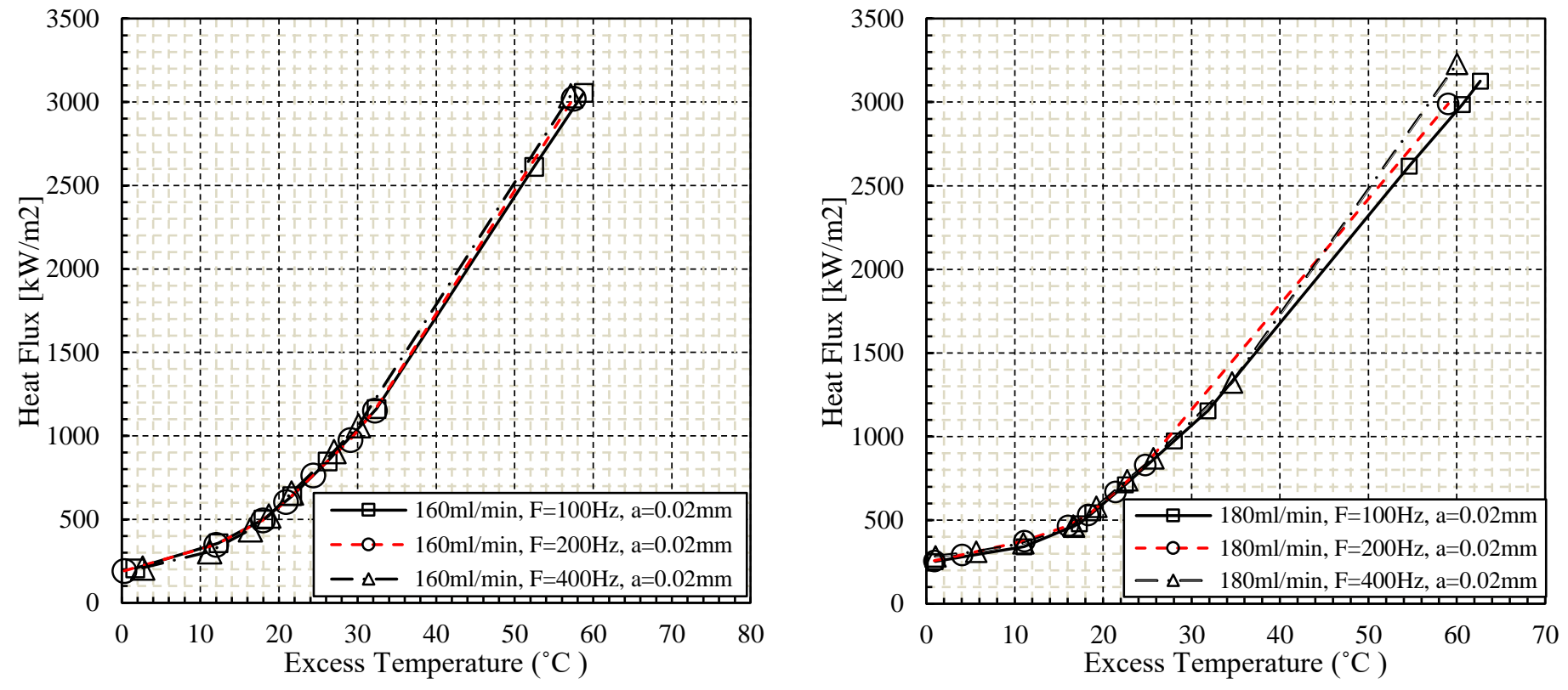

Fig. 5. Heat flux over the excess temperature for Dynamic test runs with the amplitude of 0.02 mm and frequencies up to 400 $\mathrm{Hz}$.

To inspect the static and dynamic results for any amplitude influence on the heat flux, the low frequency data of $10 \mathrm{~Hz}$, with amplitudes of $0.1 \mathrm{~mm}$ and $1 \mathrm{~mm}$ are shown on Fig. 6, with the equivalent heat-flux curves for static points. By adding to the amplitude, the represented lower values of the heat flux indicate that the amplitude itself impedes the heat transfer rate. It should be noticed that the effect is more visible on the lower excess temperatures (less than $30{ }^{\circ} \mathrm{C}$ ) which adversely affects the incipient nucleate boiling regime, the exact opposite of the frequency's influence. 

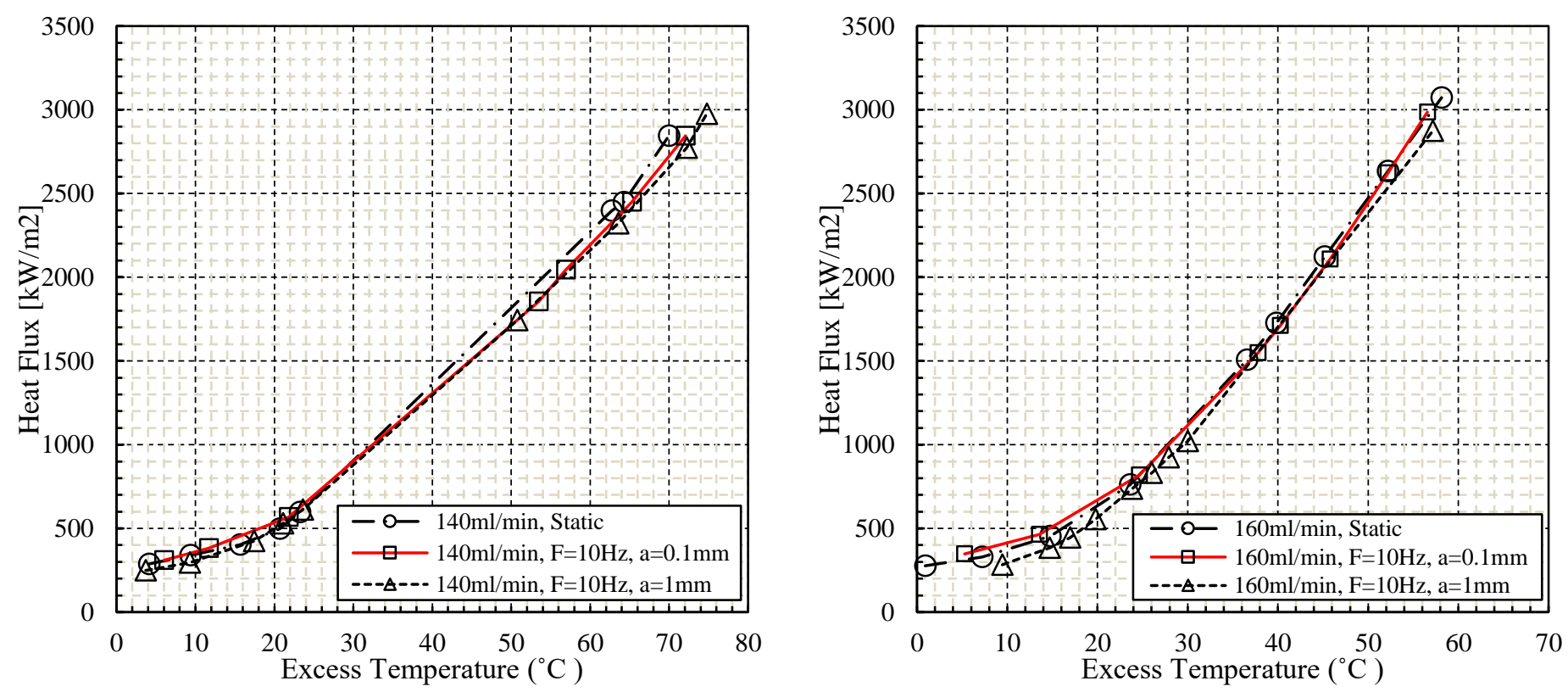

Fig. 6. Nucleate boiling curves with and without the vibration.

Fig. 6 also suggests that the effect of vibration in general is highly dependent on the complex relationship between frequency, amplitude, and excess temperature, since it is always either an enhancing or deteriorating the impact in the lower and higher surface temperature regions. However, it is only relevant to the amplitudes taken so far and there should definitely be an optimum value between. Higher amplitudes are needed to assess the sensitivity of such an important parameter, which is important to the design of the application areas under the dynamic condition e.g. thermal management of highly-boosted IC engines, and power electronics in electric vehicles.

\section{Conclusions}

An experimental investigation has been undertaken to examine the influence of dynamic behaviour on the nucleate boiling regime of a spray cooling system with and without vibration. The amplitudes and frequency have been varied between $0.02 \mathrm{~mm}$ and $1 \mathrm{~mm}$, and from $10 \mathrm{~Hz}$ to $400 \mathrm{~Hz}$ for three volumetric flow rates of $140 \mathrm{ml} / \mathrm{min}, 160 \mathrm{ml} / \mathrm{min}$ and $180 \mathrm{ml} / \mathrm{min}$. By exiting vibration from a shaker to the test piece, and with a spray nozzle supplying coolant to a heated surface, a definite effect of vibration on the heat flux over different excess temperatures was evident. The main conclusions are as follows:

- Any increase in volumetric flow-rate or mass-flux, under both Static and Dynamic conditions, causes heat transfer coefficient augmentation.

- During low excess or surface temperatures, the frequency and amplitude impedes heat transfer.

- In the higher excess temperature regions, vibration frequency enhances heat-flux. Vibration amplitude reduces the heat transfer coefficient. 


\section{Acknowledgements}

The authors wish to acknowledge the financial and technical support in the study of the Ricardo Shoreham Technical Centre, UK.

\section{References}

[1] J. Breitenbach, I.V. Roisman, C. Tropea, From drop impact physics to spray cooling models: a critical review, Experiments in Fluids, 59 (2018) 55.

[2] G. Liang, I. Mudawar, Review of spray cooling-Part 1: Single-phase and nucleate boiling regimes, and critical heat flux, International Journal of Heat and Mass Transfer, 115 (2017) 1174-1205.

[3] G. Liang, I. Mudawar, Review of spray cooling-Part 2: High temperature boiling regimes and quenching applications, International Journal of Heat and Mass Transfer, 115 (2017) 1206-1222.

[4] S. Jafari, J.F. Dunne, M. Langari, Z. Yang, J.-P. Pirault, C.A. Long, J. Thalackottore Jose, A review of evaporative cooling system concepts for engine thermal management in motor vehicles, Proceedings of the Institution of Mechanical Engineers, Part D: Journal of Automobile Engineering, 231 (2017) 1126-1143.

[5] W.-L. Cheng, W.-W. Zhang, H. Chen, L. Hu, Spray cooling and flash evaporation cooling: the current development and application, Renewable and Sustainable Energy Reviews, 55 (2016) 614-628.

[6] S.K. Mishra, A. Arora, H. Chandra, Application of Vibration on Heat Transfer-A Review, i-Manager's Journal on Future Engineering and Technology, 15 (2019) 72.

[7] A. Sathyabhama, S. Prashanth, Enhancement of boiling heat transfer using surface vibration, Heat Transfer-Asian Research, 46 (2017) 49-60.

[8] Z. Wang, Y. Xing, X. Liu, L. Zhao, Y. Ji, Computer modeling of droplets impact on heat transfer during spray cooling under vibration environment, Applied Thermal Engineering, 107 (2016) 453-462.

[9] R.J. Moffat, Describing the uncertainties in experimental results, Experimental thermal and Fluid Science, 1 (1988) 317. 